\title{
A FORMAÇÃO DE PROFESSORES EM CIÊNCIAS E MATEMÁTICA NA EDUCAÇÃO DO CAMPO A PARTIR DAS EXPERIÊNCIAS EM ESTÁGIOS E TRABALHOS DE CONCLUSÃO DE CURSO
}

\author{
Daniel Fernando Bovolenta Ovigli ${ }^{1}$ \\ Verônica Klepka²
}

\begin{abstract}
RESUMO
Dois momentos apresentam papel central na formação de professores: o Estágio Curricular Supervisionado e o Trabalho de Conclusão de Curso (TCC). Na Educação do Campo tais percursos formativos são pouco explorados quanto à sua natureza e capacidade de refletir a identidade dos estudantes. Este artigo origina-se das experiências pedagógicas de professores formadores no contexto de um curso de Licenciatura em Educação do Campo nas áreas do conhecimento Ciências da Natureza e Matemática e tem como objetivo discutir características e natureza da formação de Licenciandos em Educação do Campo tendo como objetos de análise suas produções e experiências nestes dois componentes curriculares, desenvolvidos na perspectiva da Pedagogia da Alternância. A pesquisa é de natureza qualitativa e utiliza como material empírico produções escritas dos TCCs e dos relatórios de estágio supervisionado, orientados pelos autores ao longo dos últimos anos. Observa-se que o trabalho, decorrente do modo de vida camponês, percorre as produções tanto em Ciências quanto em Matemática. Enquanto em Ciências da Natureza os estágios dão ênfase à possibilidade de articularem temáticas externas ao currículo com conteúdos canônicos do Ensino de Ciências, na Matemática são as tendências teórico-metodológicas que expressam o diálogo com os temas do cotidiano nos estágios e TCCs analisados.
\end{abstract}

Palavras-chave: Experiências pedagógicas. Ensino de Ciências. Ensino de Matemática. Educação do campo.

TEACHER TRAINING IN SCIENCES AND MATHEMATICS IN RURAL EDUCATION FROM EXPERIENCES IN SUPERVISED INTERNSHIP AND IN THE UNDERGRADUATE FINAL WORK

\begin{abstract}
Two moments have a central role in teacher training: the Supervised Internship and the Undergraduate Final Work. In Rural Education, such formative paths are little explored as to their nature and their ability to reflect the students' identity. This article originates from the pedagogical experiences of professors in the context of a Rural Education Undergraduate Course in the areas of knowledge Natural Sciences and Mathematics. Aims to discuss the characteristics and the nature of the training of Rural Education students having as objects of analysis their productions and experiences in these curricular components, in the perspective of Pedagogy of Alternation. The research is qualitative and uses as empirical material written productions of the final works and internship reports guided by the authors over the last few years. It was observed that the work, resulting from the peasant way of life, is present through the productions, both in Sciences and in Mathematics. While in Natural Sciences the internships emphasize the possibility of articulating themes external to the canonical curriculum contents of Science Teaching, in Mathematics it is the theoretical and methodological trends that express the dialogue with the themes of everyday life in the internships and final works analyzed.
\end{abstract}

Keywords: Pedagogical Experiences. Science Teaching. Mathematics Teaching. Rural education.

RECEBIDO EM: 29/3/2020

ACEITO EM: 11/5/2020

\footnotetext{
1 Autor correspondente. Universidade Federal do Triângulo Mineiro (UFTM). Av. Frei Paulino, no 30 - Bairro Abadia. CEP 38025-180. Uberaba/ MG, Brasil. http://lattes.cnpq.br/1037654075125918 . https://orcid.org/0000-0002-4057-547X . daniel.ovigli@uftm.edu.br

2 Universidade Federal do Triângulo Mineiro (UFTM). Uberaba/MG, Brasil. http://lattes.cnpq.br/4387071212003329. https://orcid.org/00000002-9937-9852. veronica.klepka@uftm.edu.br
} 
$\mathrm{Na}$ Educação Superior dois momentos integradores da qualificação profissional têm papel central: o Estágio Curricular Supervisionado (ECS) e o Trabalho de Conclusão de Curso (TCC). O primeiro deles é obrigatório nos currículos de formação de professores para a Educação Básica, enquanto o segundo é opcional (BRASIL, 2019). Embora integradores curriculares, estes dois processos são pouco explorados quanto à sua natureza e à sua capacidade de refletir o percurso formativo e até mesmo identitário dos estudantes, especialmente quando se pensa na formação de professores no/do/para o Campo.

Segundo observaram em recente trabalho Molina, Antunes-Rocha e Martins (2019), a produção do conhecimento acadêmico desenvolvido em cursos de Licenciatura em Educação do Campo (LECampo) mantém latentes indagações sobre como incorporar os conhecimentos dos camponeses nos processos de ensino-aprendizagem, o que também se estende às áreas do conhecimento Ciências da Natureza (CN) e Matemática. Por outro lado, avançou-se significativamente na ênfase dada, entre outras coisas, à forma de produção e à vida do camponês que chega à LECampo. Neste sentido, Caldart (2016) alerta-nos para o fato de que é imprescindível pensar a Educação do Campo em sua estreita relação com as práticas econômicas, políticas, sociais, ambientais e culturais dos sujeitos que tiram da terra e nela reproduzem seus conhecimentos.

O trabalho constitui-se, assim, a matriz formativa das práticas pedagógicas em Educação do Campo, seja de seu currículo integrador ou específico. "Trata-se do trabalho enquanto relação social fundamental, manifestação da vida, isto é, atividade do homem na apropriação e transformação do mundo, da realidade em si mesma [...]" (FRIGOTTO, 2012 , p. 16) e não do trabalho como alienação, mercadoria ou força de trabalho. Trata-se, pois, de um trabalho capaz de educar e de possibilitar o desenvolvimento humano em suas múltiplas potencialidades. Assim, a articulação educação/trabalho apresenta-se como fundamento a uma educação efetivamente no, do e para o campo, com vistas a uma formação humana integral. Nesse sentido, a formação no contexto da Educação do Campo não se processa unicamente na Escola ou Universidade (nosso lugar de fala), mas em muitos outros âmbitos, que são os espaços de vida das pessoas do campo. Pensar o currículo nesta perspectiva significa pensar a desfragmentação do conhecimento e considerar os problemas que emergem da realidade dos sujeitos do campo.

Levando em conta as primeiras experiências em ECS junto a LECampo: áreas do conhecimento CN ou Matemática, ofertadas pela Universidade Federal do Triângulo Mineiro (UFTM), campus Uberaba - interior do Estado de Minas Gerais -, o objetivo deste artigo reside em discutir, a partir das experiências pedagógicas dos autores, enquanto professores orientadores de ECS e de TCC nas duas áreas do conhecimento oferecidas pelo curso, as características e a natureza da formação de licenciandos em Educação do Campo, tendo como objetos de análise suas produções e experiências em Estágio IV e TCC na perspectiva da Pedagogia da Alternância.

\section{SUPORTE TEÓRICO}

Originada pelas lutas dos coletivos a fim de garantir escolas em seus territórios, a Educação do Campo tem como função social pensar numa educação que em sua matriz político-pedagógica reafirme as lutas e o modo de produzir a vida por estes sujeitos (CALDART, 2020). 
Desse modo, a Educação do Campo reivindica novas metodologias de lidar com o ensino, com o tempo e com a terra, torna o alternar físico entre tempos e espaços da casa, entre outros espaços, para a universidade e vice-versa (a alternância) uma experiência viável ante as especificidades das sociedades camponesas. "Essas práticas implicam em debater políticas públicas para as demandas que existem no campo, como a demanda da necessidade e do direito que os camponeses têm de cursar uma graduação e aplicar os conhecimentos adquiridos no espaço em que vivem" (SANGALLI; MACIEL; DOMINGOS, 2020, p. 408).

A atual estrutura curricular dos cursos de licenciatura inviabiliza a perspectiva de integração escola e comunidade (MOLINA; SÁ, 2012), uma vez que, em um modelo de universidade tradicional, o tempo acadêmico que lá se despende é visto, por vezes, como a fonte privilegiada do saber e, adicionalmente, as experiências do mundo-vida dos educandos são colocadas em segundo plano. A esse respeito, D’Ambrósio (2008, p. 4) afirma que:

Uma grande dificuldade do processo educacional é que o professor não conhece o ambiente cultural dos estudantes e, portanto, fica difícil reconhecer o que o estudante já sabe e o que é capaz de fazer. Portanto, o professor toma como referência seu próprio ambiente cultural, sua cultura, suas experiências prévias. Esse é um dos maiores equívocos da educação.

Por sua natureza e especificidade, a Educação do Campo pede outro entendimento. Em um contexto marcado, prioritariamente, por sujeitos que retiram da terra sua fonte de vida e devolvem a ela harmoniosamente e em uma lógica própria aquilo que pode ser reaproveitado, é natural que inúmeros saberes, conhecimentos e modos de se fazer passem a percorrer os conteúdos das CNs e da Matemática em sala de aula. $\mathrm{Na}$ formação inicial de professores para o campo o desafio formativo é não apenas integrar estes conhecimentos ao currículo escolar, o que já se constitui desafio de grandes dimensões, mas, também, possibilitar que as contradições vividas por estes sujeitos em seus contextos possam, a partir da Universidade, converter-se em projetos, alternativas, proposições, não para que sejam resolvidos pela escola, mas que esta possa ter como sua função social discutir, posto que são parte deste processo social as contradições no campo ou na cidade (CALDART, 2020). Nas palavras de Arroyo (2014, p. 14):

Esses coletivos populares mostram que toda experiência social, até as mais brutais, de sofrimentos, de vitimação, de opressão produz conhecimentos, indagações radicais, leituras lúcidas de si e do mundo, leituras das relações de poder, de expropriação de suas terras, leituras dos extermínios de que foram e são vítimas. Experiências tão radicais que produzem saberes radicais.

Isso nos faz questionar: Em que medida nossos currículos respondem a estes saberes? Na LECampo - UFTM - é a partir da alternância que o trabalho, o currículo e a educação podem e devem se integrar.

A Pedagogia da Alternância, contemplada pela Educação do Campo, é entendida como um continuum entre tempo-escola (TE) e tempo-comunidade (TC). Este último, em especial, tem como premissa que o mundo-vida da pessoa do campo se caracteriza como espaço-tempo central à sua formação e aprendizagem. 
Se, por um lado, a alternância pode ser vista como uma estratégia de escolarização que possibilita aos camponeses acessarem e permanecerem na escola, não abandonando suas tarefas produtivas familiares e seu vínculo cultural e com a terra, por outro tem o potencial de assumir um papel de descentramento da concepção unilateral da escola. Passa, assim, a difundir saberes, valores, conhecimentos e atitudes próprios do modo de vida e da cultura da população do campo, sem que, para isso, abandone o currículo clássico, mas ressignifique-o (SILVA, 2012). A alternância, portanto, mostra-se como campo muito fecundo para a compreensão da produção de conhecimentos no âmbito do ECS e do TCC na formação inicial de professores no, do e para o campo. Ambos são componentes curriculares de um todo orgânico que potencializa o entrelaçamento ensino, pesquisa e extensão, focos da formação universitária.

É neste momento, no TC, que se materializam as temáticas que emergem para os ECSs e TCCs. A alternância, nos dizeres de Gimonet (2007), caracteriza-se como uma pedagogia experiencial, que se processa por meio de uma rede complexa de atores e interações. Desta maneira, ante a complexidade que caracteriza o desenvolvimento dos dois componentes curriculares citados, no modelo da alternância, são demandadas novas competências do educando e do formador, uma vez que os momentos de aprendizagem vão muito além do TE. Para Molina e Sá (2012, p. 468), “Este perfil de educador do campo [...] exige uma compreensão ampliada de seu papel, uma compreensão da educação como prática social, da necessária inter-relação do conhecimento, da escolarização [...] pretende-se formar educadores capazes de promover profunda articulação entre escola e comunidade".

É nessa perspectiva que a Pedagogia da Alternância pode ressignificar a formação de professores, ao inter-relacionar TE, TC com conteúdos das CNs e Matemática em nosso caso específico, e aqueles voltados à formação didático-pedagógica. Busca-se, assim, "superar a fragmentação tradicional que dá centralidade à forma disciplinar e mudar o modo de produção do conhecimento na universidade e na escola do campo [...]" (MOLINA; SÁ, 2012, p. 469). Essa é a perspectiva curricular que temos assumido no tocante ao ECS e ao TCC na LECampo - UFTM -, na tentativa de romper com as dicotomias e propor uma ação do licenciado voltada para a valorização dos saberes presentes no campo.

\section{ABORDAGEM METODOLÓGICA}

Os dados que serão apresentados e discutidos neste artigo referem-se a uma amostra de informações resultante de duas fontes principais: i) projetos e relatórios finais da disciplina ECS, IV sob a responsabilidade dos autores durante os anos de $2018 \mathrm{e}$ 2019; e ii) TCCs de egressos, à época licenciandos em Educação do Campo das áreas do conhecimento $\mathrm{CN}$ e Matemática orientados pelos autores deste artigo.

O contexto da produção destes dados refere-se a um curso iniciado em 2014 que assume a Pedagogia da Alternância. Quatro turmas passaram pelo processo de elaboração e desenvolvimento de propostas de intervenção em ECS IV, bem como de redação e defesas de TCC. Compunham estas turmas estudantes oriundos das regiões do Triângulo Mineiro, Norte de Minas Gerais, Rondônia e Bahia, territórios em atendimento e consolidados no âmbito do curso em questão. 
Neste curso, o TCC é desenvolvido por meio das disciplinas TCC I e TCC II, que somam uma carga horária de 180 horas-aula. Já os estágios possuem, na LECampo UFTM -, para ambas as áreas de diplomação (CN e Matemática), um total de 480 horas-aula divididas em quatro semestres a partir do $5^{\circ}$ período do curso, do total de oito que o integram. Em cada estágio uma especificidade formativa é trabalhada.

Quadro 1 - Síntese dos objetivos de cada Estágio Curricular na LECampo

\begin{tabular}{|c|l|c|c|}
\hline ETAPA & \multicolumn{1}{|c|}{ COMPONENTE/ OBJETIVO } & SEM. & CH h/a \\
\hline Estágio I & $\begin{array}{l}\text { Estágio Curricular Supervisionado I: Mapear a instituição } \\
\text { educacional na qual o estágio será preferencialmente } \\
\text { realizado ao longo dos semestres seguintes, caracterizando-o } \\
\text { sociodemográfica e pedagogicamente }\end{array}$ & 50 & $120 \mathrm{~h} / \mathrm{a}$ \\
\hline Estágio II & $\begin{array}{l}\text { Estágio Curricular Supervisionado II: Realizar observação e } \\
\text { regência nos anos finais do Ensino Fundamental II }\end{array}$ & 60 & $120 \mathrm{~h} / \mathrm{a}$ \\
\hline Estágio III & $\begin{array}{l}\text { Estágio Curricular Supervisionado III: Realizar observação e } \\
\text { regência nos três anos do Ensino Médio (35 horas-aula para } \\
\text { cada componente curricular: Física, Química e Biologia para os } \\
\text { estudantes na área do conhecimento Ciências da Natureza) }\end{array}$ & 70 & $120 \mathrm{~h} / \mathrm{a}$ \\
\hline Estágio IV & $\begin{array}{l}\text { Estágio Curricular Supervisionado IV: Elaborar e executar um } \\
\text { Projeto Educativo no campo de estágio }\end{array}$ & 80 & $120 \mathrm{~h} / \mathrm{a}$ \\
\hline
\end{tabular}

Fonte: Adaptado de UFTM (2019).

No contexto do Estágio IV, no caso das turmas de CN, 30 horas-aula teóricas são destinadas durante o Tempo Escola (TE) para a construção individual de projetos de intervenção escolar sob constante orientação do(a) professor(a) da disciplina. A disciplina inicia-se com a discussão, o resgate e o levantamento de problemáticas e/ou necessidades verificadas na escola que acolheu cada um dos estudantes nos semestres anteriores, e, preferencialmente, nas turmas com as quais trabalhou ligadas ao conteúdo de Ciências da Natureza ou, ainda, questões que nascem de saberes ou práticas culturais da comunidade em que se localiza a escola e que são passíveis de articulação com os conhecimentos escolares das ciências.

Constatadas as demandas ou possibilidades temáticas, cabe ao aluno, sob orientação docente, elaborar um projeto educacional sobre o tema escolhido. As aulas seguintes são utilizadas, uma a uma, para construção: i) dos objetivos que se espera alcançar com o projeto; ii) do levantamento na literatura de trabalhos similares e das lacunas de pesquisa; iii) da metodologia de intervenção, discriminação da série/ano a que destina e adequação dos conteúdos escolares e populares à série/ao ano e ao tema escolhidos; iv) de um instrumento avaliativo da intervenção e do aprendizado alcançado pelo público-alvo; e, v) do título e da apresentação da proposta e relevância para o contexto a ser trabalhado. Trata-se de um formato bastante similar a um projeto de pesquisa acadêmica.

Ao final da carga horária teórica no TE, portanto, espera-se que os alunos retornem para o TC com seus projetos de intervenção prontos ou, no máximo, com pequenas adequações. Durante o TC o aluno deve: i) contatar a escola onde o estágio será realizado, formalizar a parceria mediante a documentação de estágio e agendar uma reunião para apresentação do projeto educacional; ii) apresentar a proposta do projeto 
educacional em reunião com a direção da escola e o professor supervisor e orientador, para apreciação, encaminhamentos e realização de ajustes, caso sejam necessários; iii) realizar reformulação e ajustes teóricos e práticos no projeto com a orientação do professor orientador de Estágio, quando necessários; e, por fim, iv) providenciar o material a ser utilizado e preparar-se teoricamente para a execução do projeto.

Todo esse processo passa por uma última orientação do(a) professor(a) da disciplina, a distância ou in loco, antes da execução do projeto e, somente depois destas etapas, a proposta segue para ser executada pelo aluno estagiário. Ao final da intervenção todo o processo é avaliado pela equipe envolvida, desde sua concepção até a efetivação, incluindo o aluno estagiário, o professor supervisor de estágio, os alunos para os quais o projeto se destinou e o(a) docente da disciplina na universidade. Estas informações, juntamente com o projeto, fazem parte do relatório final que passa por orientação e correções do professor(a) da disciplina e, uma vez adequados, bem como com os demais documentos do estágio, passam a compor a pasta do aluno na universidade como registro e nota na disciplina. Cada uma dessas etapas tem sua carga horária prática correspondente, totalizando, ao final, $90 \mathrm{~h} / \mathrm{a}$.

$\mathrm{Na}$ área do conhecimento Matemática o ECS IV, particularmente, tem ocorrido, de modo articulado com os componentes curriculares, Pesquisa e Ensino-Aprendizagem da Matemática (Peams) desenvolvidos a partir do 4o período do curso e que, em linhas gerais, abordam, semestre a semestre, as tendências teórico-metodológicas do ensino desta área, incluindo Resolução de Problemas, Tarefas exploratório-investigativas, Modelagem Matemática, Jogos, Tecnologias Digitais, História da Matemática e Etnomatemática. A esse respeito, em consonância com o PPC do curso (UFTM, 2019):

Uma vocação que tem se consolidado na articulação entre as disciplinas e seus respectivos PCCs [Prática como Componente Curricular] é a demanda pelo diálogo de saberes campesinos e científicos/matemáticos. Dessa forma, este constitui um instrumento importante para esta licenciatura no que concerne a sua aposta metodológica, que preza pelo não silenciamento das identidades do Campo. Os materiais e reflexões produzidos são articulados em outros dispositivos curriculares como Trabalho de Conclusão de Curso (TCC) e Estágios Curriculares Supervisionados, dando forma contínua às vivências durante o período total do curso (p. 76).

Os materiais didáticos produzidos/pensados/refletidos nas disciplinas de Peam podem ser experimentados no Estágio e, a partir do mapeamento realizado em etapas iniciais deste componente curricular, podem se materializar em novas intervenções em ECS IV e em TCCs. Destaque-se que este movimento não é obrigatório, mas, em uma perspectiva mais holística e de integração de saberes, não é apenas dentro das disciplinas de conteúdo específico que se busca possibilitar a relação entre os componentes curriculares, uma vez que as disciplinas de Peam podem cumprir este papel. Assim, na área do conhecimento Matemática os projetos de intervenção que são desenvolvidos pelos licenciandos evidenciam um diálogo mais estreito com as tendências teórico-metodológicas discutidas nas componentes curriculares Peam, especialmente Jogos, Resolução de Problemas, Tarefas Exploratório-Investigativas e Modelagem Matemática. 


\section{RESULTADOS E DISCUSSÃO}

\section{O ECS IV e os TCCs nas Ciências da Natureza}

Sistematizamos no Quadro 2 os 28 projetos executados pelos licenciandos das quatro turmas de CN na LECampo - UFTM - durante a disciplina de ECS IV ao longo dos semestres de 2018 a 2019, sob a orientação da autora deste artigo.

Quadro 2 - Propostas de intervenção desenvolvidas pelos licenciandos em Educação do Campo na Área do Conhecimento Ciências da Natureza ao longo dos anos de 2018 e 2019

\begin{tabular}{|c|c|c|c|}
\hline $\begin{array}{c}\text { Turma/ } \\
\text { Ano }\end{array}$ & Licenciando(a) & $\begin{array}{l}\text { Temática } \\
\text { Central }\end{array}$ & Objetivo \\
\hline \multirow{3}{*}{$2018 / 1$} & L1 & Fases da Lua & $\begin{array}{c}\text { Proporcionar, por meio dos conhecimentos } \\
\text { tradicionais, o reconhecimento das fases da Lua e } \\
\text { sua influência nas plantações da comunidade de } \\
\text { Quenta Sol }\end{array}$ \\
\hline & L2 & Ecologia & $\begin{array}{c}\text { Possibilitar o aprendizado dos biomas brasileiros } \\
\text { por meio de um jogo educativo }\end{array}$ \\
\hline & L3 & Reciclagem & $\begin{array}{c}\text { Desenvolver em educando(as) do 9o ano o } \\
\text { consumo consciente das garrafas PET voltado } \\
\text { para o desenvolvimento sustentável do } \\
\text { Assentamento Margarida Alves }\end{array}$ \\
\hline \multirow{5}{*}{$2018 / 2$} & L4 & $\begin{array}{l}\text { Ensino- } \\
\text { Aprendizagem } \\
\text { Ciências }\end{array}$ & $\begin{array}{c}\text { Contribuir com a redução da dificuldade dos } \\
\text { educadores em relação à falta de materiais } \\
\text { didáticos voltados para o ensino-aprendizagem de } \\
\text { ciências na Escola Municipal Paulo Freire }\end{array}$ \\
\hline & L5 & Agrotóxicos & $\begin{array}{c}\text { Proporcionar o ensino-aprendizagem } \\
\text { interdisciplinar contextualizado a partir dos } \\
\text { agrotóxicos }\end{array}$ \\
\hline & L6 & $\begin{array}{l}\text { Plantas } \\
\text { Medicinais }\end{array}$ & $\begin{array}{c}\text { Reconhecer a importância das ervas medicinais } \\
\text { por meio de uma horta medicinal na Escola } \\
\text { Municipal Paulo Freire }\end{array}$ \\
\hline & L7 & $\begin{array}{l}\text { Ensino- } \\
\text { Aprendizagem } \\
\text { Física }\end{array}$ & $\begin{array}{l}\text { Propiciar melhorias no ensino-aprendizagem de } \\
\text { Física aos alunos da EJA do Ensino Médio }\end{array}$ \\
\hline & L8 & Ciclo da Água & $\begin{array}{l}\text { Promover a compreensão e incentivar os alunos } \\
\text { sobre a necessidade de uso da água de forma } \\
\text { adequada, tendo em vista que ela é um bem } \\
\text { coletivo, sendo um dos determinantes para a } \\
\text { continuação da vida }\end{array}$ \\
\hline
\end{tabular}


A Formação de Professores em Ciências e Matemática na Educação do Campo a Partir das Experiências em Estágios e Trabalhos de Conclusão de Curso

\begin{tabular}{|c|c|c|c|}
\hline & L9 & Agrotóxicos & $\begin{array}{l}\text { Compreender os malefícios dos agrotóxicos } \\
\text { utilizados na comunidade de Monte Alegre à } \\
\text { saúde humana }\end{array}$ \\
\hline & L10 & $\begin{array}{l}\text { Reprodução } \\
\text { nas flores }\end{array}$ & Conhecer os órgãos reprodutivos das flores \\
\hline & L11 & $\begin{array}{l}\text { Produção do } \\
\text { Pequi }\end{array}$ & $\begin{array}{l}\text { Compreender como funciona o ciclo reprodutivo } \\
\text { e o cultivo do pequi na Comunidade de Monte } \\
\text { Alegre }\end{array}$ \\
\hline & L12 & Reciclagem & $\begin{array}{c}\text { Discutir a reciclagem e os problemas } \\
\text { socioambientais causados pelos descartes de lixo } \\
\text { visando à construção de hortas verticais a partir } \\
\text { dos saberes tradicionais locais de cultivo }\end{array}$ \\
\hline & L13 & $\begin{array}{l}\text { Plantas } \\
\text { Medicinais }\end{array}$ & $\begin{array}{l}\text { Discutir com os alunos as memórias culturais } \\
\text { das plantas medicinais pertencentes às suas } \\
\text { diferentes comunidades }\end{array}$ \\
\hline & L14 & Agroecologia & $\begin{array}{l}\text { Compreender aspectos da ecologia a partir da } \\
\text { produção e do uso do biofertilizantes }\end{array}$ \\
\hline & L15 & $\begin{array}{l}\text { Soberania } \\
\text { alimentar }\end{array}$ & $\begin{array}{l}\text { Investigar os conhecimentos prévios dos alunos } \\
\text { sobre o contexto da água e a produção de } \\
\text { alimentos no Povoado de Nova Aurora, para } \\
\text { montar canteiro econômico na Escola Estadual } \\
\text { Povoado de Nova Aurora }\end{array}$ \\
\hline & L16 & Agroecologia & $\begin{array}{c}\text { Incentivar os alunos da Escola Antônio Carlos } \\
\text { a produzirem e utilizarem o biofertilizante } \\
\text { na produção de hortaliças no Assentamento } \\
\text { Margarida Alves }\end{array}$ \\
\hline & L17 & $\begin{array}{l}\text { Fabricação } \\
\text { da farinha de } \\
\text { mandioca }\end{array}$ & $\begin{array}{c}\text { Compreender o processo da fabricação da farinha } \\
\text { de mandioca relacionando saberes tradicionais e } \\
\text { científicos }\end{array}$ \\
\hline & L18 & Paleontologia & $\begin{array}{l}\text { Promover aos alunos o aprendizado de conceitos } \\
\text { de paleontologia a partir de ficções científicas }\end{array}$ \\
\hline 2019/1 & L19 & pH da água & $\begin{array}{c}\text { Relacionar o tratamento da água das cisternas no } \\
\text { ensino de química }\end{array}$ \\
\hline & L20 & $\begin{array}{l}\text { Adubação } \\
\text { orgânica }\end{array}$ & $\begin{array}{l}\text { Realizar, em conjunto com os alunos, oficinas e } \\
\text { rodas de conversas que discutam sobre a prática } \\
\text { de adubação orgânica, os conceitos de ciências } \\
\text { envolvidos e os conhecimentos tradicionais } \\
\text { desenvolvidos pela comunidade nessa prática }\end{array}$ \\
\hline & L21 & Ecologia & $\begin{array}{c}\text { Promover a compreensão de como os seres vivos } \\
\text { se relacionam com o ambiente }\end{array}$ \\
\hline & L22 & $\begin{array}{c}\text { Plantas } \\
\text { Medicinais }\end{array}$ & $\begin{array}{l}\text { Integrar o saber tradicional acerca das plantas } \\
\text { medicinais na aprendizagem das ciências }\end{array}$ \\
\hline & L23 & Agroecologia & $\begin{array}{c}\text { Desenvolver a produção de mudas nativas e } \\
\text { frutíferas no viveiro da EFA-NE para o "resgate de } \\
\text { variedades regionais" }\end{array}$ \\
\hline & L24 & $\begin{array}{l}\text { Produção de } \\
\text { Polvilho }\end{array}$ & $\begin{array}{l}\text { Propiciar aos alunos o aprendizado de conceitos } \\
\text { da química a partir das práticas tradicionais de } \\
\text { produção do polvilho em seu cotidiano, como } \\
\text { decantação, coação, secagem, entre outros }\end{array}$ \\
\hline
\end{tabular}




\begin{tabular}{|c|c|c|c|}
\hline L25 & Meio Ambiente & $\begin{array}{c}\text { Compreender as percepções ambientais dos } \\
\text { alunos do 9o ano do Ensino Fundamental da } \\
\text { Escola Estadual Secundino Tavares, sobre o } \\
\text { entorno escolar, a fim de propor ações visando à } \\
\text { preservação ambiental }\end{array}$ \\
\hline \multirow{2}{*}{ L2619/2 } & Dengue & $\begin{array}{c}\text { Discutir a problemática da dengue na escola a } \\
\text { partir do Bairro Dinamarca para concretização de } \\
\text { ações práticas de combate a esse transmissor, o } \\
\text { Aedes aegypti }\end{array}$ \\
\cline { 2 - 4 } & L27 & Reciclagem & $\begin{array}{r}\text { Promover o conhecimento de alunos de } \\
\text { Ensino Médio de uma Escola Estadual sobre a } \\
\text { importância da reciclagem para a natureza }\end{array}$ \\
\hline & Bioma & $\begin{array}{r}\text { Discutir o Cerrado como instrumento para } \\
\text { abordagem da identidade camponesa por meio } \\
\text { da comunicação popular }\end{array}$ \\
\hline
\end{tabular}

Fonte: Os autores (2020).

Quanto à temática central escolhida por estes licenciandos, percebemos a presença marcante de intervenções que dialogam com conteúdos das ciências biológicas, seguidos da química, física e interdisciplinares, enquanto, em outros momentos, emergem temáticas de relevância social próprias ou em diálogo com a realidade camponesa.

Dentre estas propostas, correlacionando tema, objetivo e metodologia, podemos considerar a existência de eixos temáticos. Salientamos que outras formas de agrupamento são possíveis, no entanto priorizamos o foco central dado pelo estudante à proposta.

Eixo 1 - quatro projetos correspondem a um perfil mais urbano de intervenção no Ensino de Ciências (L2, L10, L26 e L27): tal fato se deve, de um lado, à própria identidade destes licenciandos em localização urbana, e, de outro, da escola proposta para a realização do estágio, também urbana.

Eixo 2 - cinco projetos preocuparam-se com aspectos do ensino-aprendizagem das ciências (L4, L7, L18, L21 e L25): precisamente estes projetos voltam-se, em sua maioria, a preencher lacunas, como a falta de materiais didáticos e, por outro lado, propiciar, por meio de novas abordagens, o aprendizado dos conteúdos.

Eixo 3 - seis projetos voltaram sua preocupação para o meio ambiente local (L3, L5, L8, L9, L16, L23 e L27), e a reciclagem foi uma das temáticas presentes nestes projetos, mas sua grande ênfase se deu pela preocupação quanto aos agrotóxicos e o uso de agroquímicos de modo geral. Neste sentido, dois projetos, no cômputo geral, desenvolvem práticas de produção e utilização de biofertilizantes naturais a partir de materiais encontrados na natureza.

Eixo 4-13 projetos integram e articulam, em maior ou menor medida, temáticas externas ao currículo de conteúdos canônicos do Ensino de Ciências (L1, L6, L11, L12, L13, L14, L15, L17, L19, L20, L22, L24 e L28); estes projetos têm como centralidade aspectos do conhecimento tradicional, do modo de vida e do trabalho camponês, tais como influência da Lua nas plantações; produção de biofertilizantes a partir de conhecimentos e matérias-primas locais; fabricação artesanal da farinha de mandioca, goma e polvilho; comunicação popular em espaços não formais, entre outros. 
Entre os 28 projetos, 13 desenvolveram algum tipo de articulação entre seu TCC e o projeto de intervenção em ECS IV. Destes, dois alunos extraíram de seus projetos de estágio reflexões diretas para a constituição de seus TCCs, especificamente ao analisarem a potencialidade da intervenção realizada durante o estágio sugerindo outros desdobramentos, inclusive curriculares, para o Ensino de Ciências. Tal movimento ocorre porque na LECampo - UFTM -, na matriz regular, o Estágio IV acontece concomitantemente à disciplina TCC II, etapa na qual o licenciando já tem o projeto com as questões de pesquisa e o objeto bem delineados. Acreditamos que essa dinâmica contribua para que a temática em estudo no TCC possa ser utilizada também no projeto de intervenção de Estágio IV. De modo contrário, o licenciando que cursa matriz não regular, ao finalizar seu Estágio IV, tem um arcabouço de reflexões que podem ser utilizadas como objetos para aprofundamento do tema que poderá vir a ser focalizado em seu TCC.

Quanto à etapa de escolarização mais escolhida para o desenvolvimento da intervenção, observa-se maior frequência de projetos com foco no Ensino Médio, tendo a EJA como principal modalidade, seguida pelo Ensino Fundamental II, especialmente no 90 ano. A realização das intervenções é caracterizada por ocorrerem em escolas do campo ou mesmo urbanas, com atendimento prioritário de alunos provenientes de territórios rurais. A discussão sobre a escola ser urbana em um município tipicamente rural também é observada. Há, ainda, experiência de um projeto desenvolvido em uma Escola Família Agrícola (EFA).

Nas propostas realizadas percebemos, de modo geral, que o projeto de estágio vislumbra a possibilidade de realização de experimentos e práticas, oficinas e exposições audiovisuais. O relatório de estágio demonstra, no entanto, que outras diferentes formas para a concretização do ECS são desenvolvidas pelos licenciandos e incluem o acolhimento, a escuta e a consideração das vivências e práticas locais de seus atores, bem como diálogos com o bioma e com o meio ambiente, em âmbito territorial. Assim, a consideração da história, das lutas envolvidas com a temática, o cruzamento de fronteiras com a espiritualidade e com as formas distintas de ver o mundo são nítidas características do conhecimento tradicional, presente nas comunidades e manifestadas por seus protagonistas em situações como a de estágio (CREPALDE et al., 2019). Aponta-se a saída do desconhecido e o acesso ao afetivo, o olhar para o entorno que vai além do excesso das informações escolares, a percepção da ciência que emerge do cotidiano, a avaliação da realidade e a intervenção nesta, bem como engajamento coletivo e das parcerias, aspectos estes que modificaram substancialmente a proposta (projeto) inicial.

Observa-se, ainda, enquanto especificidades das propostas dos alunos da área do conhecimento $\mathrm{CN}$, a valorização e o resgate de saberes e/ou práticas culturais de um contexto específico (o próprio, do campo). Tal vínculo afetivo, bem caracterizado pela escolha da temática relacionada à sua realidade contextual, refletido principalmente no Eixo 4, constitui uma das marcas identitárias das diferentes propostas. Além desta, a percepção de seu local de aluno (antes) versus o de futuro professor é também marcante, uma vez que desta posição identifica-se a possibilidade de diálogos entre o tema proposto e a ciência escolar. A respeito desta mudança de lugar na construção da identidade docente, especialmente sob o regime da alternância, Silva (2012, p. 173-174) destaca que 
A ruptura, o distanciamento do meio de vida constitui, assim, uma estratégia educativa para propiciar aos jovens melhor percepção e, consequentemente, reflexão sobre a sua realidade, estimulando uma nova visão do contexto familiar, da propriedade e das questões cotidianas no seu meio socioeconômico, que passam assim a se constituir objetos da formação.

Os conteúdos das CNs não ganham centralidade nestas intervenções, mas são utilizados para a compreensão de uma dada realidade ou problemática social. Isso pode ser visto quando, em âmbito mais interdisciplinar, a química, presente nas diferentes etapas da produção artesanal de farinha de mandioca, é usada como forma de valorização do trabalho e da identidade de camponeses, ao mesmo tempo em que demonstra relações diretas com processos de fermentação e estados físicos da matéria, entre outros conteúdos de ciências.

Neste sentido, pensar no que significa formar-se como professor de CN na Educação do Campo deve levar em conta que a formação de licenciados na LECampo - UFTM - volta-se muito mais às dimensões ético-humanista e social do que à tentativa de uma profissionalização técnica docente. Muitas vezes considerado como instrumentalização para a prática docente, o estágio na LECampo - UFTM - opera sob outra lógica, a de sensibilização docente. Ou, nas palavras de Pimenta e Lima (2006, p. 6), em estreita interação entre o curso "de formação com o campo social no qual se desenvolvem as práticas educativas", em que se extrapolam os saberes disciplinares construídos ao longo da formação, mas perpassa pelo "significado social, cultural, humano da ação desse profissional" (PIMENTA; LIMA, 2006, p. 6) e a consideração da realidade local onde a escola e seus sujeitos estão inseridos. Desse modo, o estágio na LECampo - UFTM - dialoga com o perfil de professor de ciências que a escola do campo precisa, embora este perfil ainda não esteja claro. As autoras complementam que o profissional que se quer formar e a contribuição da área para a sociedade são pontos muitas vezes desconsiderados pelos currículos, conteúdos e objetivos da formação docente (PIMENTA; LIMA, 2006).

Na LECampo - UFTM - entendemos, enquanto formadores de professores, que o trabalho é o princípio educativo que organiza e direciona primordialmente as práticas pedagógicas, sempre ético-políticas, dos estudantes advindos do campo, o que dialoga estreitamente com o Eixo 4 levantado a partir das Propostas de Intervenção do Estágio IV apresentado no Quadro 2. Este eixo, em especial, também se materializará no âmbito dos TCCs em CN, os quais apresentam-se associados ao modo de vida dos camponeses e aprofundam-se em outras reflexões teóricas (Quadro 3).

Corroboramos a análise de Crepalde (2019) quanto à consideração de que as temáticas destes TCCs estão mais relacionadas a uma formação mais integral do professor para o/do campo, do modo de vida camponês e de suas questões cotidianas do que propriamente da formação na área específica ou voltadas à escola. 
Quadro 3 - TCCs desenvolvidos por egressos da LECampo - UFTM na Área do Conhecimento Ciências da Natureza ao longo dos anos 2018 e 2019 e orientados pela autora

\begin{tabular}{|c|c|c|c|}
\hline$\stackrel{\circ}{\stackrel{C}{<}}$ & Licenciando(a) & Título & Objetivo Geral \\
\hline$\stackrel{\infty}{\stackrel{\sim}{\sim}}$ & $\begin{array}{l}\text { GUSTAVO A. } \\
\text { FERREIRA }\end{array}$ & $\begin{array}{l}\text { A Pedagogia da Alternância } \\
\text { na EJA: um olhar para o } \\
\text { estudante camponês }\end{array}$ & $\begin{array}{l}\text { Entender as causas da evasão escolar } \\
\text { em um contexto de EJA no município de } \\
\text { Campos Altos - MG - e sua relação com } \\
\text { o interesse e retorno dos trabalhadores } \\
\text { às atividades escolares, a fim de, entre } \\
\text { outras coisas, discutir a viabilidade da } \\
\text { introdução da Pedagogia da Alternância } \\
\text { como alternativa para reduzir a evasão em } \\
\text { contextos de EJA no campo }\end{array}$ \\
\hline \multirow{4}{*}{ 귬 } & $\begin{array}{l}\text { MARIA } \\
\text { CLEOMAR } \\
\text { OLIVEIRA }\end{array}$ & $\begin{array}{c}\text { A prática de adubação } \\
\text { orgânica na Comunidade } \\
\text { Tradicional Riacho dos } \\
\text { Cavalos, Rio Pardo de } \\
\text { Minas-MG } \\
\end{array}$ & $\begin{array}{l}\text { Conhecer as práticas de adubação } \\
\text { desenvolvidas pelaComunidade Tradicional } \\
\text { Riacho dos Cavalos e seus traços culturais, } \\
\text { caracterizando seu modo de produção e } \\
\text { identificando quais são essas execuções }\end{array}$ \\
\hline & DANIEL S. DIAS & $\begin{array}{l}\text { Modernização agrícola e } \\
\text { conflitos socioambientais: } \\
\text { práticas de resistência } \\
\text { desenvolvidas na } \\
\text { Comunidade Tradicional } \\
\text { Geraizeira Sobrado }\end{array}$ & $\begin{array}{l}\text { Compreender a concepção bem como as } \\
\text { práticas de cultivo desenvolvidas pelos } \\
\text { geraizeiros (agricultores) do Sobrado ao } \\
\text { longo do tempo, a fim de discutir de que } \\
\text { forma essas práticas constituem-se em } \\
\text { respostas às crises ambientais sofridas em } \\
\text { decorrência da modernização agrícola }\end{array}$ \\
\hline & $\begin{array}{l}\text { ROSEMEIRE M. } \\
\text { ALMEIDA }\end{array}$ & $\begin{array}{l}\text { Plantas medicinais, saberes } \\
\text { tradicionais e cultura da } \\
\text { Comunidade Vereda Funda } \\
\text { como possibilidades para } \\
\text { o Ensino de Ciências em } \\
\text { escolas do campo } \\
\end{array}$ & $\begin{array}{l}\text { Realizar um levantamento das plantas } \\
\text { medicinais utilizadas pela comunidade } \\
\text { Vereda Funda a fim de propor estratégias } \\
\text { de inserção dos saberes envolvidos nessa } \\
\text { tradição na escola }\end{array}$ \\
\hline & $\begin{array}{l}\text { UDILESIO O. } \\
\text { SANTOS }\end{array}$ & $\begin{array}{l}\text { As variedades crioulas do } \\
\text { Projeto de Assentamento } \\
\text { Agroextrativista Veredas } \\
\text { Vivas - Comunidade } \\
\text { Tradicional Vereda Funda, } \\
\text { Norte de Minas Gerais }\end{array}$ & $\begin{array}{l}\text { Compreender como e quais fatores } \\
\text { influenciaram a perda das sementes } \\
\text { crioulas no Projeto de Assentamento } \\
\text { Agroextrativista - Veredas Vivas/ } \\
\text { Comunidade Vereda Funda e o que } \\
\text { contribui para sua permanência nesta } \\
\text { comunidade }\end{array}$ \\
\hline \multirow[b]{2}{*}{ ટ્ָે } & $\begin{array}{l}\text { MARCOS S. } \\
\text { FERREIRA }\end{array}$ & $\begin{array}{c}\text { O convívio com a seca no } \\
\text { Norte de Minas: estratégias } \\
\text { desenvolvidas pela } \\
\text { Comunidade Jardim }\end{array}$ & $\begin{array}{l}\text { Compreender a relação da Comunidade de } \\
\text { Jardim, município de Rio Pardo de Minas - } \\
\text { MG - com a seca e discutir as estratégias } \\
\text { de convivência desenvolvidas }\end{array}$ \\
\hline & $\begin{array}{l}\text { MARIA SANDRA } \\
\text { SOUSA }\end{array}$ & $\begin{array}{l}\text { A influência lunar na } \\
\text { produção vegetal por } \\
\text { enxertia: } \\
\text { estudo de um caso em } \\
\text { Comunidade Tradicional } \\
\text { Geraizeira do Norte de Minas } \\
\text { e suas possibilidades para o } \\
\text { Ensino de Ciências }\end{array}$ & $\begin{array}{l}\text { Identificar na prática de um agricultor as } \\
\text { relações entre os conhecimentos sobre } \\
\text { a enxertia e a influência da Lua nesse } \\
\text { processo }\end{array}$ \\
\hline
\end{tabular}

Fonte: Os autores (2020). 
No TCC de Gustavo Ferreira o trabalho aparece como ponto de partida para repensar a EJA em escolas do campo, propondo a Alternância como possibilidade de reduzir a evasão escolar decorrente do trabalho de estudantes adultos, homens e mulheres, safristas de café, da EJA - Ensino Médio na escola pesquisada. Nesta pesquisa o autor não articula um conhecimento específico da sua área de formação, mas faz uso do pressuposto teórico-metodológico, base da educação do campo para os povos do campo em escolas do campo: a Pedagogia da Alternância. O problema da pesquisa nasce tanto por seu contexto, próximo a estes trabalhadores, quanto por suas reflexões durante os estágios:

Quando iniciei o primeiro Estágio Curricular Obrigatório na LECampo, em meu Plano de Ensino escolhi acompanhar uma turma da Educação de Jovens e Adultos (EJA) do Ensino Fundamental II e vi de perto a vontade desses jovens e adultos em aprender e, principalmente, em acreditar em uma vida melhor através da educação. Durante o período de safra, percebi a evasão escolar de um pequeno grupo de alunos, os quais eram trabalhadores rurais ou moradores do campo. Esses alunos, devido ao trabalho exaustivo, se sentem cansados para irem à escola à noite e outros mudam para as fazendas dos cafeicultores durante o período da safra para não precisar fazer grandes deslocamentos da cidade para o campo e do campo para a cidade todos os dias e ganhar mais tempo na colheita. Após o período de safra eles retornaram à escola para dar continuidade aos estudos e relataram a dificuldade em conciliar o trabalho com a escolarização (TCC Gustavo Ferreira, 2018, p. 6).

Na culminância de sua formação, o egresso concretiza parte de seus anseios com relação à EJA propondo a confecção de um relógio de sol para o ensino-aprendizagem da Física, haja vista a falta de materiais didáticos na escola e a relação direta deste conhecimento com a vida cotidiana dos trabalhadores (L7, Quadro 2).

Nas pesquisas de Maria Cleomar Oliveira e Daniel Dias, suas comunidades tradicionais camponesas de origem foram o foco das pesquisas com o intuito de olhar para as práticas sociais desenvolvidas, conhecê-las e compreendê-las: no primeiro TCC, práticas de adubação e, no segundo, práticas de cultivo e sua relação com o modo de vida dos moradores. Ambos os estudos resgatam a perspectiva cultural do trabalho com a terra, reconhecendo nestas atividades os saberes produzidos pelos camponeses. Os dois também carregam de algum modo essas temáticas nas intervenções por eles realizadas em Estágio IV (L14 e L20, Quadro 2).

Rosemeire Almeida e Udilesio Santos, ao pesquisarem o mesmo território, a Comunidade Tradicional Geraizeira Vereda Funda, concentram suas reflexões na riqueza de biodiversidade, cultura e saberes presentes no território e seus processos de perda em decorrência da monocultura empresarial desenfreada que assombra a comunidade há décadas. Em Rosemeire Almeida, observa-se que a resposta à possibilidade de integrar a temática plantas medicinais no Ensino de Ciências em escolas do campo nasce do seu próprio estágio como que em uma prática refletida pela sua pesquisa teórica e de campo no TCC (L22, Quadro 2).

Quanto ao último objetivo desta pesquisa, só pude percebê-lo com mais clareza quando pensei em um projeto para a disciplina de Estágio Supervisionado Obrigatório IV e decidi articular meu tema de TCC a uma proposta de aula para a Educação de Jovens e Adultos. Foi a aplicação desse projeto [...], quando meu TCC ainda estava em fase de análise de seus dados que pode responder com um exemplo concreto a possibilidade de inserção, resgate e valorização dos saberes em escolas locais do campo (TCC, Rosemeire Almeida, 2019, p. 49).

A pesquisa de Marcos Ferreira parte do olhar crítico de seu próprio trabalho com a construção de cisternas de concreto em comunidades do campo no Norte Mineiro. 
Viajando [pelas] comunidades do município de Rio Pardo de Minas em desenvolvimento com o trabalho do Programa Água para todos, muitas das quais não conhecia, passei a conviver com as pessoas que nunca tive a mínima convivência com as suas realidades. [...] Consegui observar que em muitas comunidades existem grandes recursos hídricos, mas não tem a reflexão e o uso adequado de seu recurso. Às vezes diziam que não precisavam do programa por terem muita água. E muitas outras regiões sofriam e sofrem com a escassez de água e levam o cidadão a valorizar o que ele cultiva, sempre buscando preservar, criando alternativas no seu modo de viver e produzir e atribuindo bem ao projeto do governo. [...] Com essas experiências de vida e trabalho consegui ver que o programa busca ajudar e minimizar as consequências da seca na região, não sendo um objetivo de acabar com a seca e sim de convivência com ela. Ali na comunidade antes do programa as pessoas já conseguiam passar as épocas difíceis por meio dessas estratégias criadas por elas mesmas, estratégias que desenvolvem todo ano no período de grande estiagem. Com isso o programa é mais uma estratégia desenvolvida para ajudar os moradores rurais a conviver com a seca ajudando com uma tecnologia mais eficiente para situação da escassez de água (TCC, Marcos Ferreira, 2020, p. 13).

Este egresso também parte da temática de seu TCC para a proposição de aulas sobre o pH da água presente nas cisternas e que é consumida por alunos das comunidades locais (L19, Quadro 2).

Por fim, Maria Sandra de Sousa, apesar de tratar em seu ECS de uma temática mais urbana, em decorrência de seu atual local de moradia, traz para seu TCC a forte identidade camponesa que carrega, de modo a apresentar, valorizar e extrair da atividade produtiva do pai com a enxertia de frutíferas, conhecimentos botânicos imprescindíveis à prática.

Estes TCCs, juntamente com os projetos de estágio, concretizados em intervenções, demonstram a importância da mão de obra familiar para movimentar o trabalho na agricultura familiar. Mostram, também, a heterogeneidade das formas da agricultura familiar existentes no contexto dos alunos que chegam à LECampo. Tal diversidade reflete processos de trabalho, modos de vida e culturas específicas, e condiciona, de formas distintas, a formação desenvolvida na Educação Superior de forma a exigir outra relação com o conhecimento e com o currículo.

Neste aspecto há que se destacar o papel da alternância na formação de professores de CN para o campo (CREPALDE, 2019). O currículo prescrito da universidade dialoga com um currículo ainda oculto, real, latente nos territórios dos estudantes em formação inicial. Tal diálogo é possível de ser enxergado, reconhecido e efetivado quando os professores da universidade se envolvem com a família e com os processos de produção desta. Para Silva (2012, p. 178), é preciso uma "compreensão do meio familiar como espaço de aquisição de conhecimentos, como fonte de aprendizagem de experiências sociais e culturais". Neste sentido, a alternância dos alunos em formação, bem como dos professores universitários nestes territórios, cumpre a função, entre outras, de

[...] estabelecer melhor articulação entre os dois momentos da formação, na medida em que a exploração das vivências e práticas do aluno no meio familiar/produtivo possibilita uma adequação e planejamento das atividades e dos conteúdos a serem desenvolvidos no meio escolar. $\mathrm{O}$ acompanhamento aos alunos no meio familiar, $\mathrm{o}$ conhecimento de suas condições de vida e de trabalho, a percepção de suas dificuldades e potencialidades são, no entanto, fatores que ajudam [...] a construir uma didática que tenha realmente suas raízes na realidade (SILVA, 2012, p. 176).

A seguir trazemos resultados e discussões para a área do conhecimento Matemática. 


\section{O ECS IV e os TCCs na Matemática}

Constam duas temáticas centrais, sendo a primeira delas trabalhada como intervenção no ECS IV junto ao Ensino Fundamental II e, a segunda, também como intervenção, no Ensino Médio (Quadro 4).

Quadro 4 - Propostas de intervenção desenvolvidas pelos licenciandos em Educação do Campo na Área do Conhecimento Matemática ao longo dos anos de 2018 e 2019

\begin{tabular}{|c|c|c|c|}
\hline Turma/Ano & Licenciando(a) & Temática Central & Objetivos \\
\hline \multirow{9}{*}{ 2019/1 } & L1M & $\begin{array}{l}\text { - Multiplicação de } \\
\text { frações } \\
\text { - Bingo das funções } \\
\text { de 10 grau }\end{array}$ & $\begin{array}{l}\text { - Possibilitar a fixação do algoritmo de multiplicação de frações } \\
\text { a partir de um jogo de cartas } \\
\text { - Relacionar diferentes parâmetros de uma função de } 1 \text { 10 grau } \\
\text { (coeficiente angular, coeficiente linear e raízes, por exemplo) a } \\
\text { seus respectivos significados em situações concretas }\end{array}$ \\
\hline & L2M & $\begin{array}{l}\text { - Multiplicação de } \\
\text { frações } \\
\text { - Bingo das funções } \\
\text { de } 10 \text { grau }\end{array}$ & $\begin{array}{l}\text { - Possibilitar a fixação do algoritmo de multiplicação de frações } \\
\text { a partir de um jogo de cartas } \\
\text { - Relacionar diferentes parâmetros de uma função de 1o grau } \\
\text { (coeficiente angular, coeficiente linear e raízes, por exemplo) a } \\
\text { seus respectivos significados em situações concretas }\end{array}$ \\
\hline & L3M & $\begin{array}{l}\text { - Corrida Pitagórica } \\
\text { - Alvo zero }\end{array}$ & $\begin{array}{l}\text { - Desenvolver conceitos e aplicações do Teorema de Pitágoras a } \\
\text { partir de situações envolvendo Trigonometria } \\
\text { - Possibilitar a aplicação de cálculos de média aritmética simples } \\
\text { e ponderada, modas e medianas }\end{array}$ \\
\hline & L4M & $\begin{array}{l}\text { - Varal dos } \\
\text { números racionais } \\
\text { - Funções de } 2 \text { o } \\
\text { grau }\end{array}$ & $\begin{array}{l}\text { - Identificar diferentes representações de números racionais e a } \\
\text { localização destes números na reta real } \\
\text { - Relacionar diferentes parâmetros de uma função de } 2^{\circ} \text { grau } \\
\text { (vértice, concavidade, discriminante e raízes, por exemplo) com } \\
\text { a respectiva função, aplicada a uma situação contextualizada }\end{array}$ \\
\hline & L5M & $\begin{array}{l}\text { - Potências e raízes } \\
\text { - Bingo dos } \\
\text { números complexos }\end{array}$ & $\begin{array}{l}\text { - Vivenciar os conceitos de potências e raízes a partir de uma } \\
\text { atividade realizada com os próprios alunos na quadra da escola } \\
\text { - Identificar os parâmetros de um número complexo em um jogo } \\
\text { do tipo "bingo" }\end{array}$ \\
\hline & L6M & $\begin{array}{l}\text { - Conhecendo a } \\
\text { equação de } 2 \text { o grau } \\
\text { - Corrida Pitagórica }\end{array}$ & $\begin{array}{l}\text { - Relacionar diferentes parâmetros de uma equação de } 20 \text { grau } \\
\text { (coeficientes, discriminante, raízes, forma fatorada, soma e } \\
\text { produto) com a respectiva equação } \\
\text { - Desenvolver conceitos e aplicações do Teorema de Pitágoras a } \\
\text { partir de situações envolvendo Trigonometria }\end{array}$ \\
\hline & L7M & $\begin{array}{l}\text { - Varal dos } \\
\text { números racionais } \\
\text { - Alvo Zero }\end{array}$ & $\begin{array}{l}\text { - Identificar diferentes representações de números racionais e a } \\
\text { localização destes números na reta real } \\
\text { - Possibilitar a aplicação de cálculos de média aritmética simples } \\
\text { e ponderada, modas e medianas }\end{array}$ \\
\hline & L8M & $\begin{array}{l}\text { - Dominó da } \\
\text { Multiplicação } \\
\text { - Trilha do } \\
\text { Conhecimento }\end{array}$ & $\begin{array}{l}\text { - Associar os elementos de uma multiplicação a seu resultado, } \\
\text { por meio de um jogo de dominó } \\
\text { - Fixar conceitos algébricos trabalhados no 10 ano do Ensino } \\
\text { Médio a partir de um jogo de tabuleiro }\end{array}$ \\
\hline & L9M & $\begin{array}{l}\text { - Nifty } 21 \\
\text { - Nifty } 50\end{array}$ & $\begin{array}{l}\text { - Chegar o mais próximo de } 21 \text {, sem ultrapassá-lo, utilizando-se } \\
\text { de um baralho comum } \\
\text { - Criar uma equação matemática, a partir de cartas de um } \\
\text { baralho comum, que tenha sua soma ou diferença próxima do } \\
\text { número } 50\end{array}$ \\
\hline \multirow[t]{2}{*}{$2019 / 2$} & L10M & $\begin{array}{l}\text { - Razão e } \\
\text { proporção } \\
\text { - Volumes }\end{array}$ & $\begin{array}{l}\text { - Discutir, a partir de receitas culinárias, com estudantes da EJA, } \\
\text { os conceitos de razão e proporção } \\
\text { - Problematizar, a partir das práticas sociais de estudantes da } \\
\text { EJA, unidades de medida de volume e seus instrumentos de } \\
\text { medida }\end{array}$ \\
\hline & L11M & $\begin{array}{l}\text { - Varal dos } \\
\text { números racionais } \\
\text { - Baralho das } \\
\text { funções }\end{array}$ & $\begin{array}{l}\text { - Identificar diferentes representações de números racionais e a } \\
\text { localização desses números na reta real } \\
\text { - Relacionar diferentes parâmetros de uma função de } 10 \text { grau } \\
\text { (coeficiente angular, coeficiente linear e raízes, por exemplo) a } \\
\text { seus respectivos significados em situações concretas }\end{array}$ \\
\hline
\end{tabular}

Fonte: Os autores (2020). 
No que diz respeito à temática central selecionada pelos licenciandos das turmas de ECS IV referentes a 2019/1 e 2019/2, verifica-se a presença de intervenções dirigidas, predominantemente, aos eixos temáticos "Números, Operações e Funções" e "Tratamento da Informação", havendo apenas um licenciando que resgata temática emergente das práticas sociais do campo. Destaca-se, neste caso, que o estudante realizou seu estágio na EJA. Nos demais casos, a presença do lúdico e de atividades de integração e socialização entre os estudantes foi prioritária, havendo o uso de jogos como recursos didáticos, incluindo baralhos comuns que são utilizados, por vezes, pelos próprios jovens das escolas do campo em atividades recreativas fora da escola da comunidade e que são resgatados pelos licenciandos com finalidade pedagógica, a exemplo dos jogos Nifty 21 e Nifty 50, e que são retratados nos relatórios de Estágio.

Outras propostas acabam por, de alguma maneira, trabalhar a Matemática de modo encerrado em si, ainda que contextualizado, particularmente nas temáticas voltadas às funções e à trigonometria. Correlacionando tema, objetivo e metodologia propostos também na área do conhecimento Matemática, podemos perceber a existência de eixos, aqui classificados considerando-se aqueles listados para o Ensino de Matemática nos currículos da Educação Básica, dada sua forte aproximação com estes.

Números, Operações e Funções: considera temas que envolvem, majoritariamente, o trabalho com diferentes campos numéricos, operações e relações neles possíveis, incluindo os números complexos, além de funções afins de 10 e $2 \circ$ graus, razões e proporções. Para o trabalho com todas estas temáticas os licenciandos lançaram mão de jogos por eles confeccionados anteriormente, jogos de tabuleiro, cartas de baralho e atividades matemáticas na quadra da escola. Os licenciandos L1M, L2M, L4M, L5M, L6M, L7M, L8M, L9M e L10M trabalharam com este eixo tanto na intervenção realizada no Ensino Fundamental II quanto na intervenção realizada no Ensino Médio.

Tratamento da Informação: este tema foi trabalhado apenas por L7M e L3M e unicamente como introdução às questões relacionadas ao trabalho com médias, modas e medianas no 1 을 ano do Ensino Médio. Ambos trabalharam, no Ensino Fundamental II, com temáticas relacionadas ao eixo "Números, Operações e Funções";

Espaço e Forma: apenas uma intervenção, também no Ensino Médio, desenvolvida por L10M, trata de Volumes, particularmente a partir de uma roda de conversa que considerou elementos presentes nas práticas sociais dos alunos e que tivessem relação com o tema. Igualmente, a partir da problematização acerca das medidas dos recipientes considerados, o licenciando iniciou o trabalho com o eixo temático "Grandezas e Medidas".

Aqui cabe destacar qual é o lugar que os dois últimos eixos temáticos supralistados ocupam no currículo de formação do educador (matemático) do campo. Inferimos que, em função do número de disciplinas voltadas ao eixo "Números, Operações e Funções" no currículo, os estudantes possam sentir-se mais à vontade para o trabalho com os mesmos e, adicionalmente, estes temas apresentam forte presença na Educação Básica. Esta situação pode, de certa forma, impelir os licenciandos para que também os trabalhem sob a supervisão dos professores de Matemática das escolas parceiras nos Estágios.

Observa-se paridade quanto à etapa de escolarização na qual as intervenções são realizadas, havendo Ensino Fundamental II, particularmente 6ㅇ e 9o anos, e Ensino Médio, majoritariamente no 1 o ano. Esta característica deve-se ao fato de que, por recomendação do professor orientador de ECS IV, uma intervenção precisaria ser realizada no Ensino 
Fundamental II e outra no Ensino Médio, em qualquer um de seus anos ou modalidades. Apenas um licenciando, com foco no Ensino Médio, teve a EJA como modalidade e abordou temáticas que são mais características do público-alvo desta etapa, a exemplo de razões e proporções, as quais foram trabalhadas por meio de uma receita culinária, e volumes, a partir de objetos e situações cotidianas trazidos pelos próprios educandos da EJA.

Quanto aos relatórios de estágio analisados, referentes ao ano de 2019 , percebe-se uma presença muito forte do lúdico e da interação como ferramentas fundantes para a aproximação do estudante com a Matemática, e esta caracteriza-se como a especificidade da formação nesta área do conhecimento em âmbito de Estágio.

Assim, a reflexão acerca do que significa formar-se como professor de matemática na Educação do Campo passa por pensar, assim como na área de conhecimento CN, em uma perspectiva social e interacional do ensino de Matemática.

Do total de 11 licenciandos em Educação do Campo nesta área do conhecimento e que cursaram ECS IV sob a orientação do autor deste artigo, destaca-se que cinco foram orientados também em seus TCCs (Quadro 5), os quais, dentro do enquadramento anteriormente proposto, tratam de um eixo temático diferente daquele que se concretizou no ECS. Complementarmente, tratam de temáticas não abordadas nos Estágios, com predomínio de temas dos eixos "Grandezas e Medidas", considerando a relação que este apresenta com as práticas sociais do campo, e "Espaço e Forma", mais voltado à Geometria e que pouco se fez presente nas intervenções dos estágios.

Quadro 5 - TCCs desenvolvidos por egressos da LECampo - UFTM na Área do Conhecimento Matemática ao longo dos anos 2018 a 2019 e orientados pelo autor

\begin{tabular}{|c|c|c|c|}
\hline$\stackrel{\circ}{\frac{C}{\alpha}}$ & Licenciando(a) & Título & Objetivo \\
\hline $\begin{array}{l}\stackrel{-1}{\infty} \\
\stackrel{-1}{D} \\
\stackrel{N}{2}\end{array}$ & $\begin{array}{l}\text { VIRLENE M. E. } \\
\text { BORGES DE FARIA }\end{array}$ & $\begin{array}{c}\text { Unidades de medida convencionais e } \\
\text { não convencionais de comprimento na } \\
\text { Educação de Jovens e Adultos (EJA) do } \\
\text { campo e/ou cidade }\end{array}$ & $\begin{array}{l}\text { Compreender o conhecimento sobre } \\
\text { unidades de medidas de comprimento } \\
\text { convencionais e não convencionais expressos } \\
\text { por três estudantes egressos da EJA }\end{array}$ \\
\hline \multirow{4}{*}{$\begin{array}{l}\frac{\vec{\sigma}}{\sigma} \\
\stackrel{-}{\circ}\end{array}$} & $\begin{array}{c}\text { ALINE ANTUNES DE } \\
\text { SÁ }\end{array}$ & $\begin{array}{c}\text { Os conhecimentos matemáticos } \\
\text { envolvidos na fabricação do polvilho na } \\
\text { comunidade de Santa Maria, Rio Pardo de } \\
\text { Minas/MG }\end{array}$ & $\begin{array}{l}\text { Sistematizar as matemáticas envolvidas } \\
\text { na produção do polvilho na Comunidade } \\
\text { de Santa Maria, Rio Pardo de Minas/MG }\end{array}$ \\
\hline & $\begin{array}{l}\text { CLÁUDIO DANIEL } \\
\text { DIAS SILVA }\end{array}$ & $\begin{array}{l}\text { Levantamento das unidades de } \\
\text { medida não convencionais utilizadas } \\
\text { na Comunidade Moreira, Rio Pardo de } \\
\text { Minas/MG: um olhar etnomatemático }\end{array}$ & $\begin{array}{l}\text { Identificar quais } \quad \text { unidades } \\
\text { instrumentos de medida não } \\
\text { convencionais são utilizados por } \\
\text { agricultores da Comunidade Moreira, } \\
\text { Rio Pardo de Minas/MG }\end{array}$ \\
\hline & $\begin{array}{l}\text { RAILTON OLIVEIRA } \\
\text { SILVA }\end{array}$ & $\begin{array}{c}\text { "Dominó da Multiplicação" e "Batalha das } \\
\text { Operações" como estratégias de fixação } \\
\text { das operações básicas de Matemática no } \\
60 \text { ano de uma escola do campo }\end{array}$ & $\begin{array}{l}\text { Analisar o uso dos jogos "Batalha } \\
\text { das Operações" e "Dominó da } \\
\text { Multiplicação" em uma turma do } 6^{\circ} \text { ano } \\
\text { do Ensino Fundamental Il de uma escola } \\
\text { do campo, localizada no Distrito de Serra } \\
\text { Nova, cidade de Rio Pardo de Minas/MG }\end{array}$ \\
\hline & $\begin{array}{l}\text { LUIZ HENRIQUE } \\
\text { FERREIRA BISPO }\end{array}$ & $\begin{array}{l}\text { O ensino de funções de primeiro grau no } \\
\text { Ensino Médio da Escola Estadual Carmela } \\
\text { Dutra com a utilização das TIC: uma } \\
\text { abordagem exploratório-investigativa }\end{array}$ & $\begin{array}{l}\text { Investigar as potencialidades e limitações } \\
\text { do uso do software GeoGebra no ensino } \\
\text { de funções afins de } 1^{\circ} \text { grau em uma } \\
\text { turma do } 1^{\circ} \text { ano do Ensino Médio de } \\
\text { uma escola pública estadual situada no } \\
\text { município de Santa Fé de Minas/MG }\end{array}$ \\
\hline
\end{tabular}

Fonte: Os autores (2020). 
Destaca-se que a articulação com o estágio se deu de modo mais evidente nos TCCs de Railton Oliveira Silva e de Luiz Henrique Ferreira Bispo, uma vez que, a partir do mapeamento que realizaram em etapas anteriores do ECS, puderam definir temas de seu interesse para o desenvolvimento do trabalho final. Railton Silva, em especial, identificado como L8M no Quadro 4, desenvolve ECS e TCC na mesma escola, e relata a necessária inserção do lúdico como estratégia de ensino em aulas de Matemática, componente também presente em atividades do campo quanto aos momentos de integração em comunidade. Tais momentos relevam o emprego de jogos de cartas e palitos, dominós e adivinhações, os quais se configuram como elementos para potencializar o interesse dos alunos pela aprendizagem Matemática em articulação com suas raízes culturais, particularmente no 60 ano do Ensino Fundamental II, etapa na qual atuou o licenciando.

Durante as experiências de Estágio nas escolas presenciei que os alunos ficam ansiosos para que a aula acabe e possam ir para o recreio; ao inserir os jogos e as brincadeiras nas salas poderá despertar nos estudantes a vontade de aprender e estudar e, ao mesmo tempo, mostrando a eles o valor de suas raízes culturais, fazendo com que possam enxergar o lúdico por meio do jogo, e a educação do campo de uma forma diferenciada (TCC, Railton Silva, p. 12).

Luiz Henrique Ferreira Bispo, por sua vez, também desenvolve seu ECS e a intervenção que origina seu TCC na mesma unidade escolar, uma escola localizada na zona urbana, mas que atende predominantemente estudantes oriundos do campo. Sua inquietação consistia na quase nula utilização de estratégias didáticas que fossem além do livro didático e sua transcrição na lousa, mormente tecnologias digitais, e, para tanto, desenvolveu uma sequência didática a partir de tarefas exploratório-investigativas para o trabalho com problemas contextualizados ao campo para funções afins do 1 으 grau, utilizando o software livre Geogebra. Para tanto, os problemas a serem resolvidos com o auxílio do software foram levantados junto a turma em um questionário aplicado no primeiro encontro da sequência por ele desenvolvida, fora do Estágio, porém aliado às reflexões por ele realizadas em ECS:

Na realização do Estágio Supervisionado na instituição de ensino da cidade onde moro, pude observar que os professores de Matemática, em geral, limitam a diversificação das metodologias de ensino, ficando à mercê do livro didático fato que, por descrição dos alunos, tornam as aulas menos atraentes. Diante das considerações dos alunos, notei que a metodologia do uso das TIC poderia auxiliar e facilitar o aprendizado dos alunos nas aulas de Matemática, tendo em vista a utilização do software GeoGebra no ensino de funções (TCC, Luiz Henrique Ferreira Bispo, p. 16).

$\mathrm{Na}$ área do conhecimento Matemática, em especial, o papel de outro componente curricular da LECampo, intitulado "Seminário Integrador", também se mostrou de grande relevância na opção pelos temas dos trabalhos. A docente atuante na disciplina, ministrada três semestres antes do início do TCC, solicitou aos estudantes que escolhessem um tema atinente ao campo e com o qual gostariam de trabalhar em uma intervenção educacional. Esta motivação enquadrou-se em dois dos TCCs orientados, o que demonstra a necessária integração não apenas entre TE e TC, conteúdos específicos e conteúdos didático-pedagógicos mas, também, entre os demais componentes curri- 
culares integrantes da matriz do curso, tendo em vista uma formação, de fato, integral. No caso do TCC de Virlene Faria, além de ter trabalhado com a EJA, a autora optou por incluir tema de grande relevância social no contexto do campo, as unidades de medida e seu uso. A esse respeito, afirma a licenciada:

Em "Seminário Integrador" fiz um trabalho de campo, sendo que podíamos escoIher qual tema trabalhar e, então, me deparei com a EJA (Educação de Jovens e Adultos). No decorrer da conversa com estudantes desta modalidade de ensino me assustei quando falaram que a renda deles é baseada em costura, especialmente para as mulheres, e ordenha, no caso dos homens, sendo que ambas as atividades utilizam unidades de medida. Pensei, "mas como eles utilizam as unidades de medida? Será que eles as conhecem e como são utilizadas?" (TCC, Virlene Faria, p. 15).

Um segundo TCC, que teve sua gênese em Seminário Integrador, é o de Aline Antunes de Sá, que se interessou por realizar sistematização dos saberes matemáticos envolvidos na fabricação do polvilho em sua respectiva comunidade, com vistas a trazer elementos para a construção de um currículo que fizesse a integração destes saberes com a Matemática escolar para a escola do campo. De acordo com a autora:

A partir de discussões feitas na disciplina Seminário Integrador surgiu a ideia de falar de um tema que estivesse relacionado com minha cultura como agricultora. Pensei em vários temas para minha monografia, mas não tinha encontrado nenhum com o qual eu me identificasse. Foi então que surgiu a ideia, a partir de discussões realizadas em sala de aula, durante as quais consegui deduzir o tema deste trabalho. $O$ tema escolhido consistiu em conhecer os conhecimentos matemáticos envolvidos na fabricação do polvilho na comunidade de Santa Maria, que possibilita trazer a valorização dos saberes tradicionais do meio em que vivo (TCC, Aline Antunes, p. 13).

Na esteira de Aline Sá, Cláudio Daniel Dias Silva também trouxe um tema com o qual guardava afinidades no âmbito de sua comunidade, neste caso pensando no levantamento das unidades de medida não convencionais, o que demonstra, mais uma vez, o eixo voltado a "Grandezas e Medidas" como privilegiado na formação de educadores (matemáticos) do campo. É interessante pontuar que o curso não apresenta componentes curriculares voltados especificamente à discussão deste tema; trata-se de questões emergentes do próprio contexto social dos estudantes. Segundo o licenciado:

Dentro do curso de Licenciatura em Educação do Campo, habilitação em Matemática, no decorrer das disciplinas, refletia sobre um tema com o qual eu tivesse afinidade para trabalhar na monografia. A ideia era pesquisar algo com que sempre trabalhei junto a comunidade Moreira e relacionar com a minha área em formação em Matemática (TCC, Cláudio Daniel, p. 10).

É neste sentido que, mais do que o Estágio IV, os TCCs da LECampo Matemática dialogam mais extensamente com as práticas sociais atinentes ao campo e podem, neste perfil, configurarem-se como currículos para se (re)pensar a Educação Matemática no, do e para o campo, em particular quando pensamos na alternância como possibilidade formativa que retroalimenta o currículo. Trata-se do TC como promotor de temas e problemas para o TE e talvez aí resida a base para se pensar em um currículo de Matemática efetivamente pensado para a escola do campo. 


\section{CONSIDERAÇÕES FINAIS}

Nossas experiências como formadores e orientadores de ECS e TCC, aqui discutidas, mostram que os estudantes da LECampo - UFTM -, tal como afirma Arroyo (2014), não correspondem a meros consumidores de um conhecimento pronto, mas apresentam-se como aqueles que produzem conhecimentos. Na medida em que o "lugar" do estudante é levado para o currículo de formação na universidade, premissa que a Educação do Campo busca para si, o perfil do professor em Ciências da Natureza e Matemática constrói-se em intrínseca relação com seu território e com a vida em suas comunidades. Dessa forma, a participação dos estudantes como estagiários e, em um segundo momento, como professores nessas escolas, valoriza a educação escolar do campo e a identidade camponesa.

Outro aspecto importante que demarca nossas experiências é que o trabalho, decorrente do modo de vida camponês, percorre de formas distintas as produções tanto em Ciências quanto em Matemática. Enquanto em Ciências da Natureza os estágios dão ênfase à possibilidade de articularem temáticas externas ao currículo a conteúdos canônicos do Ensino de Ciências, na Matemática são as tendências teórico-metodológicas que expressam o diálogo com os temas do cotidiano nos estágios e TCCs analisados.

Os dados apresentados, produtos do trabalho ao longo dos últimos anos, já nos permitem considerar que o currículo da Educação do Campo, em constante construção, deve, necessariamente, perpassar pela dimensão do trabalho como componente formativo, traço distintivo destes docentes em formação que resulta em constante diálogo com as lutas e o modo de produção e de vida dos homens e mulheres do campo.

\section{REFERÊNCIAS}

ARROYO, M. G. Outros sujeitos, outras pedagogias. 2. ed. Petrópolis, RJ: Vozes, 2014.

BRASIL. Conselho Nacional de Educação. Define as Diretrizes Curriculares Nacionais para a Formação Inicial de Professores para a Educação Básica e institui a Base Nacional Comum para a Formação Inicial de Professores da Educação Básica (BNC-Formação). Resolução CNE/CP n. 02/2019, de 20 de dezembro de 2019. Disponível em: http://portal.mec.gov.br/index.php?option=com_docman\&view=download\&alias=135951-rcp002-19\&category_slug=dezembro-2019-pdf\&Itemid=30192. Acesso em: 10 mar. 2020.

CALDART, R. S. Função social das escolas do campo e desafios educacionais do nosso tempo. Texto aula inaugural do curso de Licenciatura em Educação do Campo. Universidade Federal do Rio Grande do Sul. Tramandaí-RS: Campus Litoral, 9 mar. 2020.

CALDART, R. S. Sobre a especificidade da Educação do campo e os desafios do momento atual. In: FRIGOTTO, G.; CIAVATTA, M. (org.). Teoria e educação no labirinto do capital. 4. ed. São Paulo: Expressão Popular, 2016. p. 317-363.

CREPALDE, R. S., KLEPKA, V., PINTO, T. H. O.; SOUSA, M. A integração de saberes e as marcas dos conhecimentos tradicionais: reconhecer para afirmar trocas interculturais no ensino de ciências. Revista Brasileira de Pesquisa em Educação em Ciências, 19, p. 275-297, 2019.

CREPALDE, R. S. Desafios e potencialidades da construção de Trabalhos de Conclusão de Curso na alternância da Licenciatura em Educação do Campo da UFTM. REUNIÃO NACIONAL ANPED, 39., 2019. Niterói. Anais [...]. Niterói, RJ, 20 a 24 de outubro, 2019.

D’AMBRÓSIO, U. O programa etnomatemática: uma síntese. Acta Scientiae. Canoas v. 10, n. 1, p. 7-16, jan./jun. 2008.

FRIGOTTO, G. Apresentação. In: GOMEZ, C. M. (org.). Trabalho e conhecimento: dilemas na educação do trabalhador. 6. ed. São Paulo: Ed. Cortez, 2012.

GIMONET, J. C. Praticar e compreender a Pedagogia da Alternância dos CEFFAs. Petrópolis: Editora Vozes; Paris: AIMFR, 2007. 


\section{\& Contexto}

MOLINA, M. C.; SÁ, L. M. Licenciatura em educação do campo. In: CALDART, Roseli et al. (org.). Dicionário da educação do campo. Rio de Janeiro; São Paulo: Escola Politécnica de Saúde Joaquim Venâncio; Expressão Popular, 2012. p. 468-474.

MOLINA, M. C.; ANTUNES-ROCHA, M. I.; MARTINS, M. F. A. A produção do conhecimento na Licenciatura em Educação do Campo: desafios e possibilidades para o fortalecimento da educação do campo. Rev. Bras. Educ., Rio de Janeiro, v. 24, e240051, 2019.

PIMENTA, S. G.; LIMA, M. S. L. Estágio e docência. São Paulo: Cortez, 2006. (Coleção docência em formação. Séries saberes pedagógicos).

SANGALLI, A.; MACIEL, J. M. B. M.; DOMINGOS, D. C. A. O estágio curricular supervisionado na educação do campo: estratégias na alternância. In: FALEIRO, W.; VIGÁRIO, A. F.; FELÍCIO, C. M. (org.). Entre fios e tramas da formação inicial e continuada de professores. Goiânia: Kelps, 2020. p. 404-423.

SILVA, L. H. As experiências de formação de jovens do campo: alternância ou alternâncias? Curitiba, PR: CRV, 2012.

UFTM. Universidade Federal do Triângulo Mineiro. Projeto Pedagógico do Curso de Licenciatura em Educação do Campo. Uberaba: UFTM, 2019. 